\title{
Isolation and identification of a potent allelopathic substance in Bangladesh rice
}

\author{
Md Abdus Salam • Masahiro Morokuma • \\ Toshiaki Teruya $\cdot$ Kiyotake Suenaga $\cdot$ \\ Hisashi Kato-Noguchi
}

Published online: 15 August 2009

(C) Springer Science+Business Media B.V. 2009

Erratum to: Plant Growth Regul (2009) 58:137-140

DOI 10.1007/s10725-009-9360-5

The above article was published in Plant Growth Regulation 58:137-140.

We determined the chemical structure of the compound by spectral data as 2,9-dihydroxy-4-megastigmen-3-one. The structure is correct but the name was incorrect. It is 9-hydroxy-4-megastigmen-3-one.

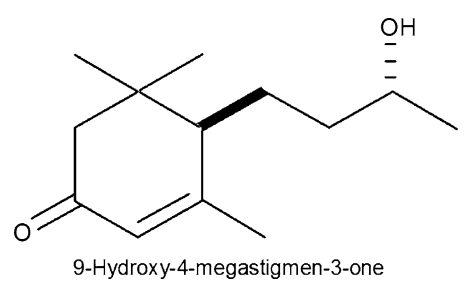

The online version of the original article can be found under doi:10.1007/s10725-009-9360-5.

M. A. Salam · H. Kato-Noguchi $(\bowtie)$

Department of Applied Biological Science,

Faculty of Agriculture, Kagawa University,

Miki, Kagawa 761-0795, Japan

e-mail: hisashi@ag.kagawa-u.ac.jp

M. Morokuma

University Farm, Faculty of Agriculture,

Kagawa University, Sanuki, Kagawa 769-2304, Japan

T. Teruya $\cdot$ K. Suenaga

Department of Chemistry, Faculty of Science and Technology,

Keio University, 3-14-1 Hiyoshi, Kohoku,

Yokohama 223-8522, Japan 